\title{
UNCONVENTIONAL METHOD OF PRODUCTION OF CAVITIES IN FULL MATERIAL ON A MACHINE
}

\author{
JAN MORAVEC \\ UNIZA - University of Zilina, Zilina, Slovak Republic, EU, jan.moravec@fstroj.uniza.sk
}

https://doi.org/10.37904/metal.2021.4098

\begin{abstract}
The paper describes the theoretical knowledge about the process of forming holes in the solid material. The own design solution of an experimental device for forming cylindrical sleeves is presented. The results obtained in experimental work are presented at the end of the paper. The text is supplemented by diagrams and photographs of the experiment and the cases.
\end{abstract}

Keywords: Technology, forming, cavities, pushing, forming equites

\section{INTRODUCTION}

Many solutions in forming technological practice are based on the application of unconventional solutions. Experimental work is mentioned and described in the professional literature, where machine tools were used as energy sources. It would not be good to a priori reject the advantages of machine tools when applying them in the field of forming. $[1,2,3]$. The aim of the paper is to verify the possibility of creating cavities in the bar material using the device presented below, the implementation of the process at different speeds, the investigation of the chip formed during the formation of cavities, deviations and accuracy of molded parts. The necessary theoretical knowledge about the formation of cavities in a full body is published. The construction solutions and the described experimental work, which were performed in connection with the verification of the formation of cavities on the machine tool in an unconventional way with the application of the manufactured and published forming tool, are presented. [4,5,6,7].

\section{THEORETICAL KNOWLEDGE}

Extrusion is one of the basic and important works of volume forming, by means of which cavities are formed in the material, resp. imprints. The embossing technology is divided into loose and directed. With free indentation, the circumference-surface of the part is free, in contrast to the directed indentation in the sleeve, which prevents the material from moving to the sides. $[8,9,10,11,12]$. The starting material is deformed during free indentation, the height $h$ decreases, the material is broken, the outer diameter $D$ increases evenly in height - Figure 1 on the left. With directed pressing, the height of the semi-finished product increases - Figure 1 on the right. The solution described below is a combination of both methods - in the first phase it is free and in the second directed embossing, where the support (sleeve) is a support roller. When the value of the $D / d$ ratio is large, it is a large process of pressing a punch (mandrel) onto an endless body bounded by a surface (half-space). This starts with $D / d \approx(5 \div 6)$ ratios.
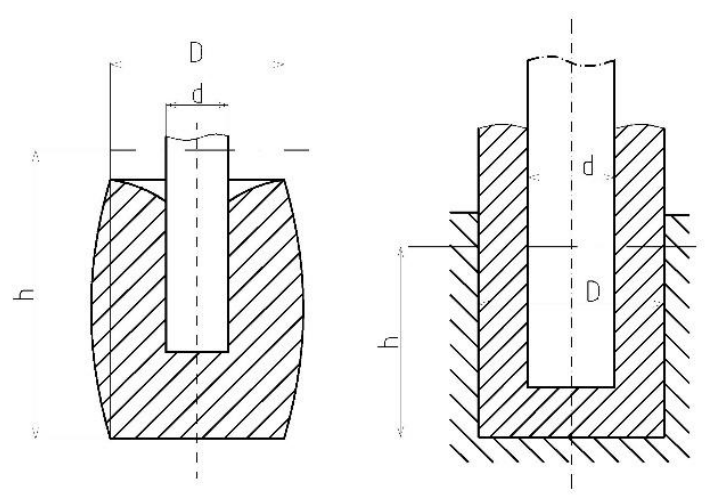

Figure 1 Injection pattern (free to the left and right to the right) 


\subsection{Forming pressure for experimentally directed indentation}

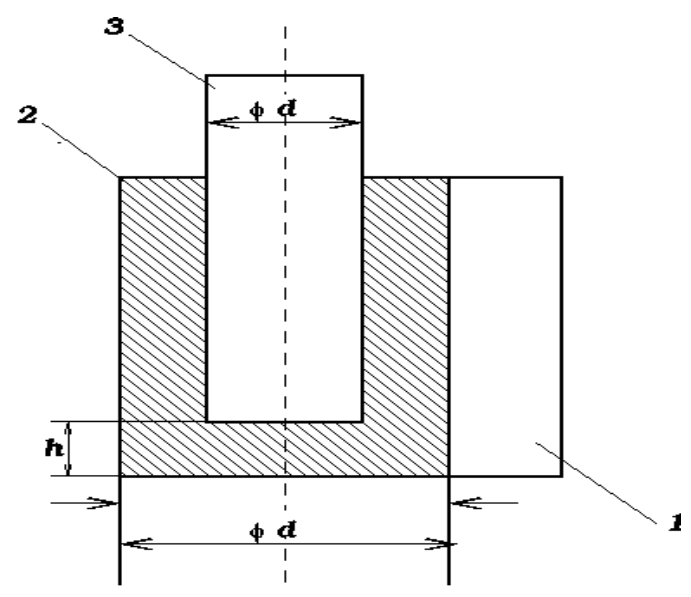

Figure 2 Scheme of pressing the mandrel into the solid material with the idea that the roller 1 replaces the wall extruder and the material does not flow in the direction perpendicular to the mandrel, but in its longitudinal axis1-support roller, 2-formed material, 3-mandrel

Figure 2 schematically indicates the final stage of making a cavity in a cylindrical blank on a machine tool. The process itself is captured in an idealized way. The support 1 is in direct contact with the surface of the art 2 and the mandrel 3 is already at the bottom dead center. This is the case when the roller 1 touches the surface of the material from the beginning, but in this case it is not, it can realistically be presented according to Fig. 3. In simplifying this relatively complicated process, this is necessary because the question of determining the forming pressure for directed indentation in a closed extruder with a cylindrical mandrel is complex. $[13,14,15]$.

\section{EXPERIMENTAL MATERIAL AND EQUIPMENT}

The molded material was brass with the composition in Table 1.

Table 1 Chemical composition of experimental material.

\begin{tabular}{|c|c|c|c|c|c|c|}
\hline Brand & Cu \% & Zn \% & Pb \% & Fe \% & Sn \% & Ni \% \\
\hline CuZn40Pb2 & 59.29 & 37.60 & 2.346 & 0.385 & 0.270 & 0.110 \\
\hline CuZn36Pb3 & 59.42 & 37.48 & 2.41 & 0.55 & 0.232 & 0.107 \\
\hline CuZn39Pb & 56.80 & 39.80 & 2.90 & 0.150 & 0.100 & 0.063 \\
\hline
\end{tabular}

The diameter of the rod brass was $15 \mathrm{~mm}$. The strength limit of the material was $\mathrm{Rm}=210 \mathrm{MPa}$. The equipment for performing the tests is relatively simple. According to Figure 4, it is clear that a brass rod is clamped in the three-jaw chuck 1 of the lathe, which protrudes from the jaws $60-80 \mathrm{~mm}$ according to the required length of the housing.

A cylindrical steel mandrel is clamped into the quill of the tailstock and a pressure roller and a parting knife are clamped in the support. The speed is $1200 \mathrm{rpm}$. The mandrel face is brought to the face of the workpiece and lightly pressed against it, creating friction and heating the end of the workpiece to a temperature of 700 to $800^{\circ} \mathrm{C}$. Then the mandrel is pushed into the workpiece and the metal is pushed from the inside towards the circumference. Roller gives the workpiece a regular cylindrical shape. The diameter of the workpiece can be varied by up to a few millimeters with different intensities of pressing the roller onto the workpiece. When finished, the workpiece is tapped to the required length. Mandrels for different inner and outer diameters of bushings can be made to the device. The bevel on the mandrel face is not permissible because the inner diameter of the housing increases and the surface is rough. Also, the centering hole cannot be at the head of 
the mandrel, because it makes molding very difficult. This is due to the fact that the molded material is pressed there and the deformation resistance rises to an unbearable level. According to Figure 4, the device consists of a handle, a roller, a shaft and a mandrel. The roller and mandrel are hardened to 62 HRC. Seven pieces of samples were formed under the conditions described and with the apparatus. After shaping, the sleeve was tapped to a length of $1=20 \mathrm{~mm}$, and the face on the remaining part was aligned. The surface of the hole and the housing are smooth without cracks. The material can be formed without difficulty. The hardness of the material before forming was on average 47-48 HRB, after forming it is given in Table 2. The average of 14 measurements is given. The measurement results are shown in Tables 2, 3 and 4. Figures 5-7 illustrate the whole experimental process of making cavities.

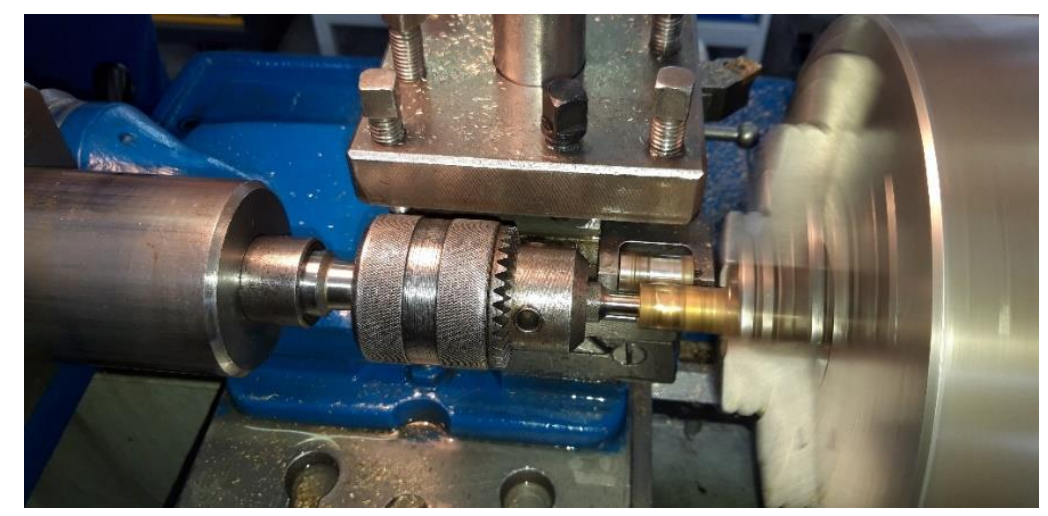

Figure $3 \mathrm{~A}$ look at the actual application of the forming equipment

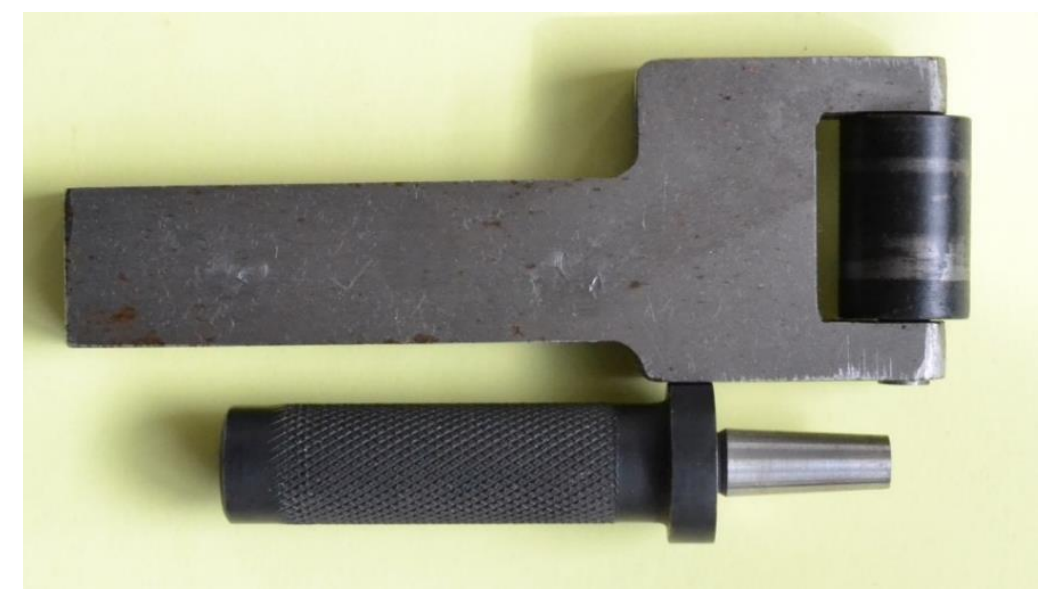

Figure 4 Forming equipment used in the experiment
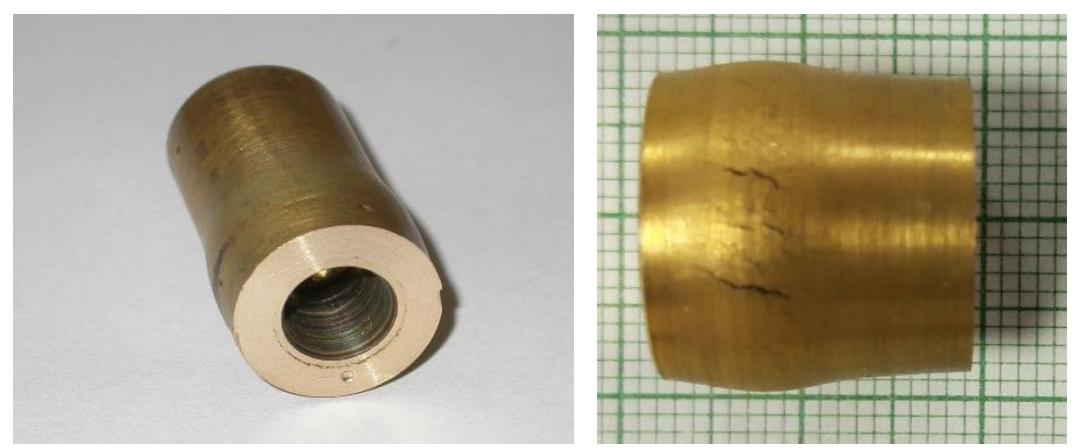

Figure 5 Formed sleeves, on the right a sleeve with cracks which have formed during the application of an unsuitable mandrel with a centering hole 


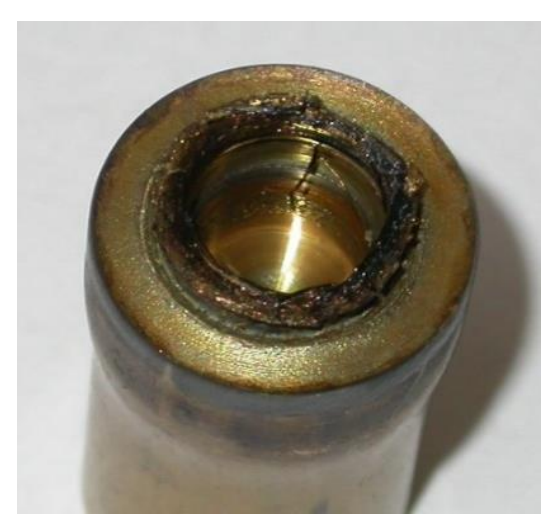

Figure 6 Detail of the front of the case with the folded edges of the hole

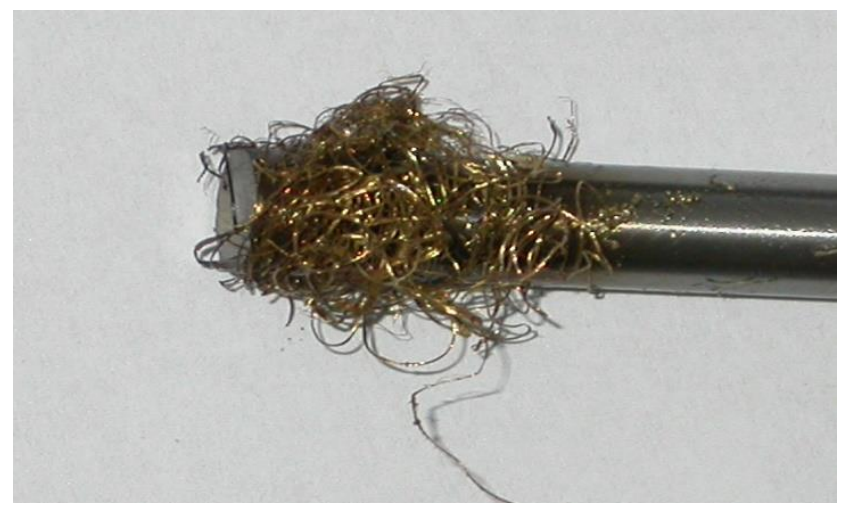

Figure 7 The shape of the chips formed during the forming of the hole

Table 2 Dimensions of formed cases after experiments

\begin{tabular}{|c|c|c|c|c|c|c|c|c|c|c|c|c|c|}
\hline \multirow{2}{*}{$\begin{array}{c}\text { Spec. } \\
\text { No. }\end{array}$} & \multicolumn{5}{|c|}{ External dimensions } & \multicolumn{4}{|c|}{ Internal dimensions } & \multicolumn{4}{|c|}{ Surface roughness } \\
\hline & $\begin{array}{l}\varnothing \text { Ø uP } \\
\text { (in a } \\
\text { hole) }\end{array}$ & $\varnothing \mathrm{MID}$ & $\begin{array}{l}\varnothing \\
\text { DoWN }\end{array}$ & $\begin{array}{l}\text { Distance max. } \\
\text { od čela }\end{array}$ & High L & $\begin{array}{l}\varnothing \text { UP } \\
\text { (in a } \\
\text { hole) } \\
\end{array}$ & $\varnothing \mathrm{MID}$ & $\stackrel{\varnothing}{\stackrel{\bullet}{1}}$ & Depth H & $\mathrm{R}_{0^{\circ}}^{\mathrm{R}}-$ & $\underset{90^{\circ}}{\mathrm{Ra} 2-}$ & $\begin{array}{l}\text { Ra } 3- \\
180^{\circ}\end{array}$ & $\begin{array}{l}\text { Ra 4- } \\
270^{\circ}\end{array}$ \\
\hline 1 & 15.05 & 5.48 & & 6.86 & & 8.20 & 8. & 8.30 & 20 & 3 & 4 & 1 & 088 \\
\hline 2 & 1505 & 16.59 & 6 & 5. & .10 & 8.00 & 8.12 & 8.36 & 10.90 & 1.872 & 1.922 & 273 & 859 \\
\hline 3 & 1 & - & 15.08 & 0 & 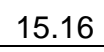 & 8.16 & 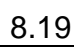 & 8.35 & 9.67 & 23 & 2 & 3 & 507 \\
\hline 4 & 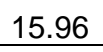 & 1.00 & . & & 10. & 0.01 & 0.00 & 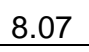 & 731 & 0.710 & 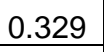 & 0.150 & $0.0 \%$ \\
\hline 5 & 15.94 & 16.05 & & Flat surface & & 8.36 & 8.15 & 8.11 & & 3.992 & 3.83 & 6.178 & 2.961 \\
\hline 6 & 15.97 & 15.95 & 15.94 & Flat surface & 15.18 & 8.14 & 8.18 & 8.22 & 8.09 & 0.443 & 0.398 & 0.472 & 0.559 \\
\hline 7 & 15.92 & 15.98 & 15.99 & & 15.20 & 8.40 & 3.17 & 3.23 & 8.10 & 0.520 & 0.392 & 3.762 . & .85 \\
\hline
\end{tabular}

Table 3 Dimensions of housing openings after experiments

\begin{tabular}{|c|c|c|c|}
\hline \multirow{2}{*}{$\begin{array}{c}\text { Specimen } \\
\text { No. }\end{array}$} & \multicolumn{3}{|c|}{ Roudness of the hole } \\
\cline { 2 - 4 } & $\varnothing$ UP & $\varnothing$ MID & $\varnothing$ DOWN \\
\hline 1 & 0.044 & 0.022 & 0.006 \\
\hline 2 & 0.003 & 0.010 & 0.008 \\
\hline 3 & 0.005 & 0.030 & 0.007 \\
\hline 4 & 0.002 & 0.003 & 0.004 \\
\hline 5 & 0.002 & 0.009 & 0.006 \\
\hline 6 & 0.003 & 0.008 & 0.005 \\
\hline 7 & 0.004 & 0.009 & 0.008 \\
\hline
\end{tabular}

Table 4 Hardness of creations

\begin{tabular}{|c|c|c|c|c|c|c|c|}
\hline Sample No. & 1 & 2 & 3 & 4 & 5 & 6 & 7 \\
\hline Hardness [HRB] & 48 & 49 & 48 & 47 & 50 & 48 & 49 \\
\hline
\end{tabular}

\subsection{Findings}

excessive cooling and lubrication is necessary during the process in order to avoid heating of the turbid mandrel during high friction of parts; 
- $\quad$ the mandrel with the grooving of the clamping part has proved its worth, so there is no overturning;

- $\quad$ at least $1150 \mathrm{rpm}$ are sufficient;

- $\quad$ the hole is slightly conical, it is suitable to make a mandrel with a bevel of approx $0,5^{\circ}$,

- the roughness of the hole is on average $\mathrm{Ra} 1.6$,

- $\quad$ the chip shape is ribbon-like.

\section{CONCLUSION}

The paper describes the possibility of application of forming equipment and machine tools in the production of cavities in a cylindrical material by directed forming. The aim of the paper was to point out the possibilities of integrating various technologies, forming and machining, which can be used for the production of cavities in artists. In the production of small series of housing moldings with an internal cavity, the above solution can be used successfully because it is undemanding and fast.

\section{REFERENCES}

[1] AVITZER, B. Metal Forming. Processes and Analysis. New York: McGraw Hill, 1968.

[2] BLAŠČíK, F. a kol. Forming, casting and welding technology. Bratislava: ALFA, 1988.

[3] BOLJANOVIC, V. Sheet Metal forming processes and die Design. 2005. ISBN 0-8311-3182-9.

[4] ČERMÁK, J., DVOŘÁKOVÁ, J. Selected forming methods. Praha: CVUT, 1980.

[5] ELFMARK, J. Plasticity of metals. Ostrava: HF VSB, 1986.

[6] FARLÍK, A., ONDRÁČEK, E. Theory of dynamic forming, Praha: SNTL, 1968.

[7] HOSFORD, W.F., CADDEL, R.M. Metal Forming, Mechanics and Metallurgy. Cambridge University Press, 2011. ISBN 978-1-107-00452-8.

[8] JOHNSON, W., MAMALIS, A. G. Plasticity and metal forming. Cambridge, 1998.

[9] JOHNSON, W., MELLOR, P. B. Plasticity for Mechanical Engineers. London: D. von Nostrand Co. Ltd., 1962.

[10] KUMAR, S. Technology of Metall Forming Processes. New Delhi, India: 2008, p. 358. ISBN 978-81-208-3425-0.

[11] MIELNIK, M. E. Mechanical Metallurgy. New York: Mc Graw - Hill Book Company, 1991.

[12] MORAVEC, J. Unconventional methods of metal forming. EDIS publishing house ZU in Zilina, 2011, p. 135. ISBN 978-80-8070-554-0233-8.

[13] MORAVEC, J., BÍLIK, J. Forming machines and tools. EDIS publishing house ZU in Zilina, 2016. ISBN 978-80554-0446-2.

[14] MORAVEC, J. A small guide to metal forming. Three edition. Publishing house ZU Zilina, 2012, pp. 146. ISBN 978-80-8070-554-0544-5.

[15] STOROZEV, M.V., POPOV, J. A.: Theory of metal forming. Alfa Bratislava, 1978. 